Journal of Engineering and Applied Sciences 14 (4): 1211-1218, 2019

ISSN: 1816-949X

(C) Medwell Journals, 2019

\title{
Evolution of Business It Alignment: Gap Analysis
}

\author{
Karim Doumi \\ Al-Qualsadi Research and Development Team, \\ Faculty of Juridical, Economic and Social Sciences (FSJES), \\ National School for Computer Science (ENSIAS), Mohammed V Rabat University, \\ Rabat, Morocco
}

\begin{abstract}
Now a days, business IT alignment requires the implementation of a powerful alignment model allowing a perfect coherence of all the actions and the decisions with the strategic objectives of the company which must be declined in an operational way with the business processes in order to align them with the information system. This study proposes an approach for the management of the evolution business IT alignment through the analysis of the gaps between the models of alignment As-Is and To-Be. This gap analysis is based on a set of metrics that make it possible to study the existing links and calculate the differences between the different layers of the enterprise architecture. Also this research has been validated through a case study of a real project in a Moroccan public administration.
\end{abstract}

Key words: Business IT alignment, goals modeling, enterprise architecture, information system, evolution, metric

\section{INTRODUCTION}

The concept of alignment of Information Systems (IS) is traditionally processed through the result obtained after alignment. Thus, according to Mckeen and Smith (2003), alignment exists when the IS complies with the goals and activities selected to position the company in its market. Etien (2006) defines alignment as the set of existing links between elements of the business process model and elements of the supporting computer system model. Chan and Reich (2007) define the alignment as the degree with which the mission, objectives and plans contained in the competitive strategy are shared and supported by the IT strategy. According to the Anonymous (2004) report, the expression "alignmen" expresses the idea of making the IS strategy in coherence with the company's strategy.

Today, organizations are facing permanent environmental changes. They modify their strategies, their activities (new activities, transformations), their network (merger, partnership, etc.) and their staff (management, department, etc.). All these movements are performed under constraints: actions of competitors, customer demand, new technologies, etc. In this context, to remain competitive and ensure their sustainability, companies must adapt internally to these external constraints.

These internal changes affect, generally, several levels of the organization, namely: the strategic and operational levels. These developments which affect the IS of the company are dealt with in the framework of the alignment of information systems which consists in making the IS evolve in coherence with the changes at the strategic level, so that, the company can be efficient and effective and able to compete and evolve. Indeed, even if it is possible on one hand to build efficient ISs and on the other hand to define the strategy of the company, it is essential that these two sets are aligned in order to optimize the company's performance.

One of the main difficulties in realizing this alignment within the company is the lack of common understanding and communication between executives from the world of management and those from the world of information technologies (Chang et al., 2008; Peppard, 2003; Redoli et al., 2008; Brocke and Rosemann, 2012; Lankhorst, 2012).

In fact, most business leaders have an intuitive understanding of the way in which their organizations work. However, they are often unable to communicate in a clear and simple way. As a result, IS managers rarely understand what is expected of them and how they could contribute to improving the efficiency and productivity of the company. Conversely, IS managers have a clear idea of what ISs are capable of providing but generally they have a hard time developing an IS that is consistent across all business lines.

The beneficial impact of alignment on the profession and the information system has been empirically demonstrated qualitatively and quantitatively (Kearns and Lederer, 2003; Leede et al., 2002; Fritscher and Pigneur, 2011; Chan et al., 1997). The results showed that companies that have successfully aligned their business strategies with their information system strategies are more efficient than those that are not aligned (Chan et al., 1997). 
In addition, several researchers have discussed the engineering of alignment as a sub-domain of IS engineering as well as the engineering of requirements or needs or a discipline in its own right, taking into account the importance of alignment for researchers users and industrials.

In the literature, various researches are interested in IS alignment (Henderson and Venkatraman, 1993; Luftman, 2000; Regev, 2004; Wegmann et al., 2007; Krishna et al., 2004; Salinesi and Thevenet, 2008; Bodhuin et al., 2004; Bleistein, 2006; Yu, 1997; Thevenet and Salinesi, 2007; Wagter et al., 2012; Borek et al., 2011; Doumi et al., 2011a, b). In these researches, most researchers propose methods and tools specific to the problematic of the alignment for example models to build the alignment between business processes and the information system and even tools for detecting change and maintaining the alignment. Despite all these researches and despite that the alignment is widely recognized, its implementation remains too often limited (Thevenet and Salinesi, 2007).

Several researchers have confirmed that research in the field of alignment is insufficient (Hirschheim and Sabherwal, 2001; Salinesi and Thevenet, 2008.). In the industry, it should be noted that very few executives consider that the strategy and the IS of their company are aligned. And this is confirmed by IBM Reports (IBM 2003). Moreover, in the literature several researchers (Luftman, 2000; Etien, 2006; Thevenet and Salinesi, 2007; Brocke and Rosemann, 2012) have dealt with the problematic of the representation of alignment and confirm that the actors of the organization do not know what the alignment is.

This lack of representation of the alignment relationship is explained by the fact that strategy models and system models are traditionally expressed in different languages at distinct levels of abstraction and in separate documents. Models at the strategic level use concepts such as purpose, objective, indicator while system models describe objects, operations, events and so on. This lack of communication and understanding between these levels poses the problem of constructing and evaluating alignment.

In this regard, several researches (Fimbel, 2007; Hirschheim and Sabherwal, 2001; Salinesi and Thevenet, 2008; Brocke and Rosemann, 2012) have emphasized the importance of a common vision of the information system shared by the leaders and the operational actors for example the heads of institutions and project managers to carry out the success of the alignment maneuvers in order to reduce the constraints of feasibility and the opportunities which can exist in the different levels of abstraction.

This study proposes an approach for managing the evolution of IS strategic alignment using gap analysis between the As-Is and To-Be alignment models. This gap analysis is based on a set of metrics that allow us to study the existing links and calculate the differences between the different layers of the architecture of the company. This approach is illustrated by case study of a real project in a Moroccan public administration.

\section{Literature review}

Evolution of business IT alignment: Alignment with developments aims to ensure that the IS can evolve in accordance with the changes in the organization and its environment. Indeed, these developments require the continuous alignment of the IS. This fact highlights the need to implement evolving IS to cope with potential changes over time.

A preliminary analysis of the alignment approaches compared to support provided to the time dimension shows that most of these approaches are based on an analysis of the current state (As-Is) of strategic alignment models. However, the design of a reactive IS is not sufficient to meet the long-term developments in the business and IT environments. Indeed, in order to cope with these developments, it is necessary to set up a more detailed IT planning (Newkirk and Lederer, 2007) but also to imagine and develop scenarios representing the possible long-term states (To- Be) (Dyson, 1990).

In addition, the current state (As-Is) is the result of the evolution of a previous or past state (Fimbel, 2007). Thus, the previous scenarios describing the previous states must also be taken into account because they are at the origin of the current state (As-Is) and its constraints (rigid organizational processes are strongly coupled to the existing IS, human resources skills strongly linked to the existing IS, etc.).

In the literature only the iterative SEAM (Wegmann et al., 2007) method makes it possible to describe future states (To-Be) for each organizational level and to reduce the gap between the existing (As-Is) and these future states. To treat alignment with developments using SEAM, it is necessary to describe, with the help of scenarios, the potential changes that could take place at a given organizational level. Therefore, the created gap can be reduced in the future by developing and deploying new resources to maintain alignment between levels. However, this approach does not explicitly support the management of evolution in the sense of calculating the gap between the present and the future.

Consequently, we propose in this study an approach that is based on the analysis of the gap between the current state (As-Is) and the future state (To-Be), through metrics, allowing to better grasp the existing situation and exploit it for future states. 


\section{MATERIALS AND METHODS}

\section{Metrics for evolution of business IT alignment}

Measurement framework alignment: We focus on the measures proposed by Cavano and McCall (1978) that were developed by Etien (2006) as a framework for measuring software quality. The researchers define a framework that is based on 3 concepts: factors, criteria and metrics.

Factor is management oriented view of product quality, criteria is software oriented attributes which provide quality and metrics are quantitatives measures of those attributes, used to measure a criteria.

According to the IEEE Standard Glossary of Software Engineering terminology, the quality metric can be defined as "a function that takes as argument the software and data that returns a single numerical value. This value is used to measure the extent to which software possesses a given quality attribute.

The framework of Cavano and McCall (1978) has eleven factors and thirty criteria. This is a reference in the field of quality measurement. It has inspired many hierarchical model such as Boehm et al. (1978) Model, Dromey (1995) Model and the standard ISO/ IEC 9126. The framework of McCall is also used by manufacturers such as in major military projects of USA (Fitzpatrick, 1996).

Etien (2006) developed this framework to propose a measurement framework consisting of 4 factors to measure the degree of alignment between the business process model and information system model: intentional alignment, informational alignment, functional alignment and dynamic alignment.

Similarly, our measurement framework alignment consists of factor, criteria and metrics. We have identified 2 factors on which the relationship of strategic alignment can be measured: intentional factor and functional factor. Each factor is associated to criteria. Each criteria is associated to metrics that measure the degree of alignment.

The intentional factor measures the gap between the strategic and process level while the functional factor used to measure the gap between the process and information system level. As shown in Table 1-5 criteria and 5 metrics were identified.

Table 1: Measurement framework alignment

\begin{tabular}{ll}
\hline Factor/criteria & Metric \\
$\begin{array}{l}\text { Intentional factor } \\
\text { Rate supporting goals by business process }\end{array}$ & $\begin{array}{l}\text { Percentage of goals supportedby } \\
\text { Business processes }\end{array}$ \\
$\begin{array}{l}\text { Presence rate of resource } \\
\text { Presence rate of actors }\end{array}$ & $\begin{array}{l}\text { Percentage of resources usedby business processesre lated to goals } \\
\text { Percentage of actors that contribute toachieving a goal }\end{array}$ \\
$\begin{array}{l}\text { Functional factor } \\
\text { Rate supporting business process by information system } \\
\text { Degree of cooperation between direction of information } \\
\text { system and managers }\end{array}$ & $\begin{array}{l}\text { Percentage of business process by information system } \\
\text { No measurable }\end{array}$ \\
\hline
\end{tabular}

Table 2: Rates support of goals

Acronym/name $\quad$ Formal definition

Description

AGBP:
of Average number of "hard goal" supported by "business process"

AGBP $=$

H husiness process \#(hard gold) sby "busin ess process"i

\#(hard goal): the number of "hard goal"

\#(business process): the number of business process

\#(hard goal)sby"business process" $i$ : the number of hard goal

supported by business process index $\mathrm{i}$

Table 3: Rate presence of resources

\begin{tabular}{|c|c|c|}
\hline Acronym/name & Formal definition & Description \\
\hline $\begin{array}{l}\text { ARBP: } \\
\text { Average number of "resource" used } \\
\text { by "business process" supporting a } \\
\text { "hard goal" }\end{array}$ & 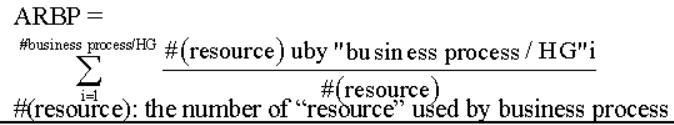 & $\begin{array}{l}\text { Is computed counting the number of "resource" } \\
\text { used by "business process"supporting a "hard } \\
\text { goal" divided by the number of "resource" }\end{array}$ \\
\hline
\end{tabular}

Table 4:Rate presence of actors

\begin{tabular}{|c|c|c|}
\hline Acronym/name & Formal definition & Description \\
\hline $\begin{array}{l}\text { AAG } \\
\text { Average number of "actor" who } \\
\text { make decision and achieve a } \\
\text { "hard goal" in strategic level" }\end{array}$ & $\begin{array}{l}\text { AAG }= \\
\text { \#hard goal \#(actor) ach "hard goal" } \mathrm{i} \\
\sum_{\text {i=1 }} \frac{\text { \#(actor) }}{\# \text { (hard goal): the number of "hard goal" }} \\
\text { \#(actor): the number of "actor" } \\
\text { \#(actor) ach "hard goal"i: the number of actor } \\
\text { contributed to achieve hard goal }\end{array}$ & $\begin{array}{l}\text { The goal of this metricis to evaluate the degree of } \\
\text { presence of actors in construction of contributed to } \\
\text { alignment between the goals and business processes } \\
\text { that support them }\end{array}$ \\
\hline
\end{tabular}


Table 5: Rate support of business process by information system

\begin{tabular}{lll}
\hline Acronym/name & Formal definition & Description \\
$\begin{array}{l}\text { ABPIS } \\
\text { sverage number of "business process" }\end{array}$ & $\begin{array}{l}\text { ABPIS }= \\
\text { supported by "IS business area }\end{array}$ & $\begin{array}{l}\text { The goal of this metricis to evaluate the degree of } \\
\text { alignment between the business processes and } \\
\text { information sy stem through business area }\end{array}$ \\
& $\begin{array}{l}\text { \#(IS bu sin ess area }) \\
\text { \#(IS business area): the number of "IS business area" } \\
\text { \#(business P): the number of business process } \\
\text { \#(business P) sby"IS business area" i: the number of business } \\
\text { process supported by business area index i }\end{array}$ & \\
\hline
\end{tabular}

Intentional factor and its criteria assess the degree to which strategic goals are supported by business processes (support rate). It also measures the degree of presence of actors and resources.

Functional factor assesses the degree to which business processes are supported by information system through business areas and also the degree of collaboration between the direction of information system and managers. Such assessments are made using two criteria, the rate of support for business processes by the information system and degree of collaboration.

The metric of the intentional factor used to study the gap between elements of the strategy and business processes while the metric of the functional factor used to study the gap between business processes and information systems.

Metrics: The metrics that, we propose give a synthetic vision of how to evaluate the satisfaction of the high level objectives by the information system through the analysis of existing links between the modeling elements of the BUSITAME method (Doumi et al., 2013a, b). We define five metrics that we identified in the measurement. Three metrics are related to the intentional factor and two metrics for functional factor.

\section{RESULTS AND DISCUSSION}

Case studies; Project of the Ministry of Higher Education (Morocco): The project, we have chosen is very important for the Moroccan government which is part of a national program to improve the situation in higher education. The study of the alignment of this project will help actors to decide if information system is aligned with this project. The case study is inspired from a real project at Rabat University, Morocco.

Description and representation of the case: Public administration can be viewed as the development, implementation, and study of branches of government policy, aiming at the pursuit of public good by enhancing the civil society and ensuring a fair and effective public service. In a more concise definition, public administration is the typical activity of organisms and individuals which under supervision of the political power, realize in name of a collectivity, the task of satisfying regularly and continuously the collective needs for security, culture and economical and social well-being, in the terms of the applicable legislation and under the control of the appropriate courts.

As part of public administration and in the context of the reform of higher education in Morocco, a reorganization of the university cycles based on LMD System (License-Master-Doctorate) took place. Also, important efforts were made to develop the technical and professional options in each university.

\section{The objectives of studied project are:}

- To improve the internal output of higher education and the employability of the award-winnings who arrive on the job market

- To offer to the students good conditions of training and lodging

\section{Some of the awaited results are:}

- Creation of almost 124,000 places at the university

- Multiplication by 2 of the capacity of reception of university

- Registration of the $2 / 3$ of all students of higher education in technical, scientific and professional options

- Creation of almost 10,000 places in the halls of residence

In order to apply our approach for strategic alignment to the University Mohamed 5, the first step consists in the translation of all objectives of the project into goal model formalism. After, we linked the goal (hard goal) with business processes related to our project and in the last step, we have linked all business process with information system through business area.

Note that in the modeling of this project, we have ignored the representation of some elements of information system (neighborhood and block of each business area) in order to make the figure over loaded and therefore, unreadable.

Evaluation of the alignment of the project: Our measurement framework alignment consists of factor, criteria and metrics. We have identified 2 factors on which 
the relationship of strategic alignment can be measured, intentional factor and functional factor. Each factor is associated to criteria. Each criteria is associated to metrics that measure the degree of alignment. The intentional factor measures the gap between the strategic and process level while the functional factor used to measure the gap between the process and information system level.

To do this we have developed a prototype EBUSITAME (Editor for BUSITAME) to support the modeling business IT alignment proposed in the BUSITAME method (Doumi et al., 2013). The objective of this prototype is to build strategic alignment models. It also allows the user to define strategic alignment maps, alignment links and metrics as well as planning to manage the evolution of strategic alignment.

For the evaluation of the strategic alignment of the project, we used the metrics proposed in BUSITAME in section 3. Remember that thresholds and weights are defined by the manager based on their knowledge and appreciation of the project. For our case study the threshold for metrics "Goal Support Rate by Business Process" was set at 0.9. Whereas for the metric "support rate of business processes by IS" the threshold was set at 0.6 .

The results of the evaluation show the failure in two metrics that are: the rate of support of functional goals by business processes $(80 \%)$ and the rate of support of business processes by the information system across areas trades $(70 \%)$.
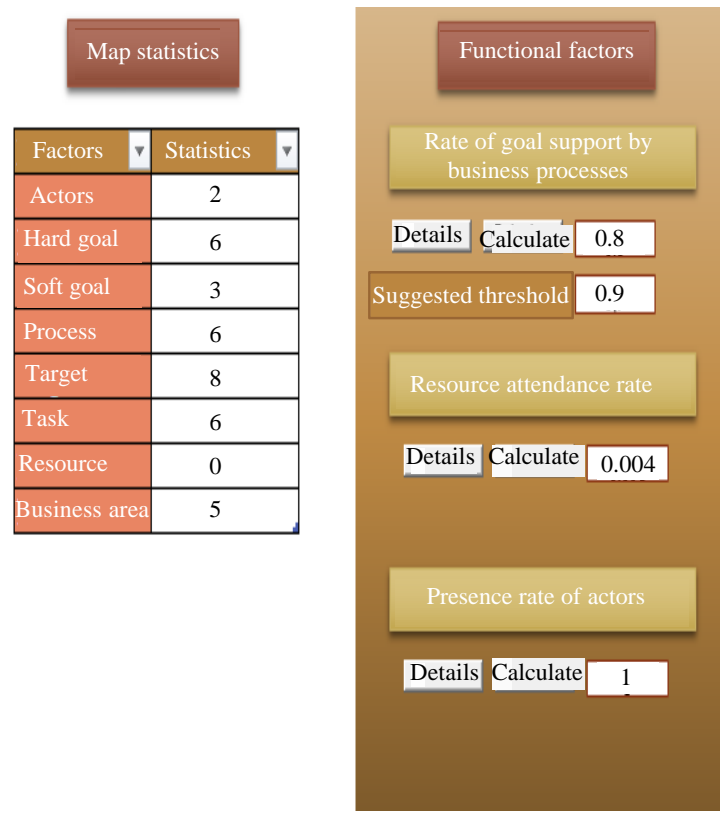

Fig. 1: Metrics evaluation results

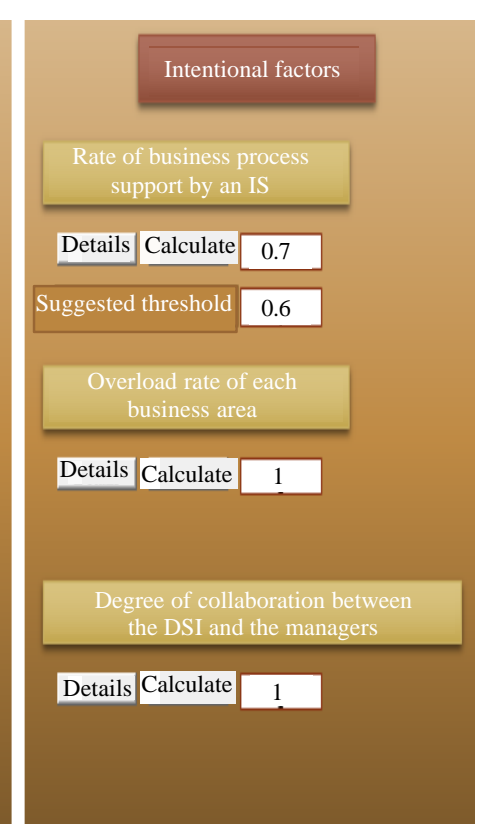

Assessment and evolution study of the strategic alignment of the project: The goal of the evolution study is to provide a roadmap for decision makers through gap analysis and identification of gaps in alignment issues. In this sense, we present our metrics as graphs to better visualize the results of the evolution. The results of our project clearly show that we need to focus on the metrics of functional objectives supports by business processes and the business process support metrics by the business areas of the information system (Fig. 1).

Also, the evolution of the strategic maps shows that from the Version 4 of the project one notices a significant improvement of all the metrics. This shows that the changes made in the alignment process are good (Fig. 2).

In the rest of this study, we propose the evolution of each metric separately in order to be able to identify the failures of the alignment process for each metric and in the sense of better planning the future modifications for an aligned system (Fig. 2-5). This makes it possible, for example, to compare the expected objective with the current situation in order to detect as soon as possible whether there are actions to be taken to achieve the objective. This step leads to the identification of evolution requirements for alignment correction.

The goal of this metric is to evaluate the degree of alignment between the goal of the strategic level and business processes that support them. The values of this metric show a trend towards the augmentation from 0.4-1 which proves that the corrective actions have reduced the gap between the V1 and V3. 


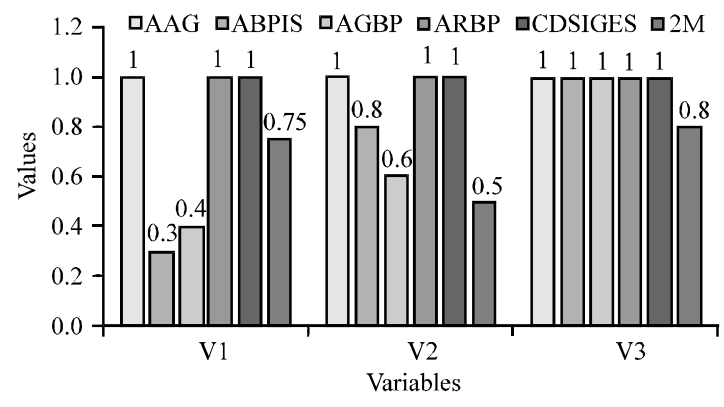

Fig. 2: Evolution of the metrics through several versions of the modeling

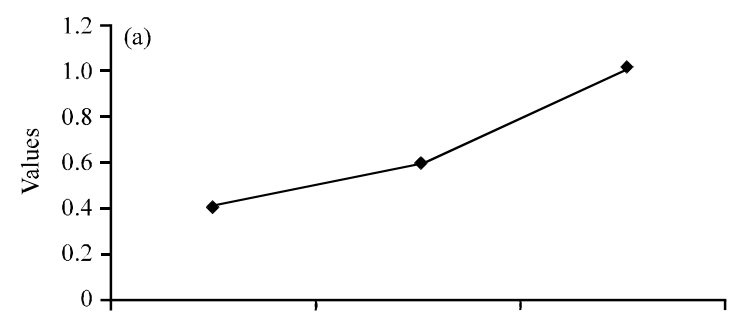

(b)

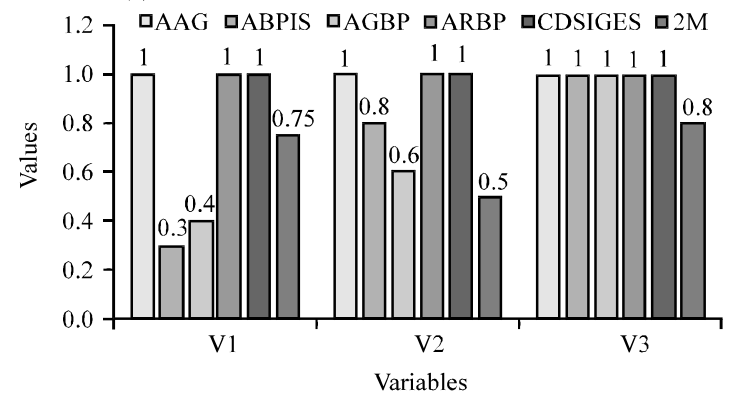

Fig. 3: a, b) Evolution of AGBP metrics

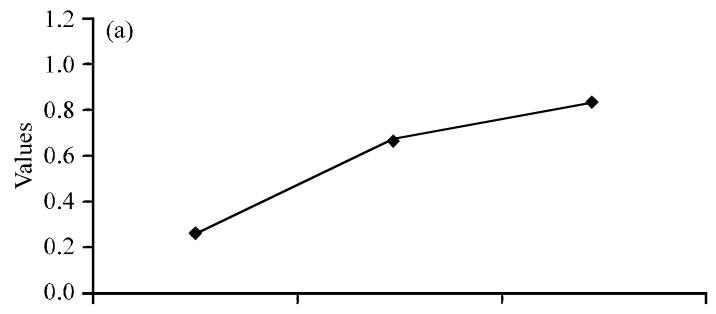

(b)

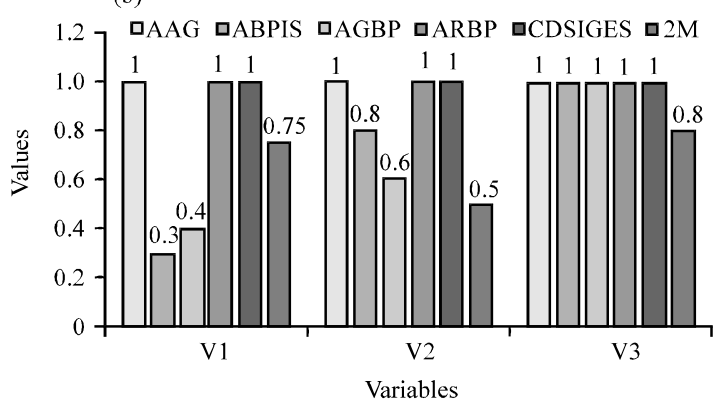

Fig. 4: a, b) Evolution of ABPIS metrics

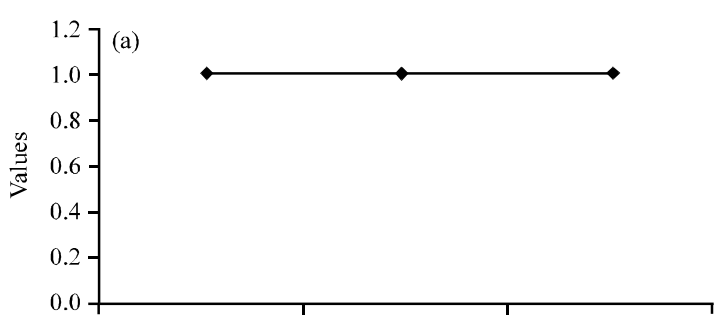

(b)

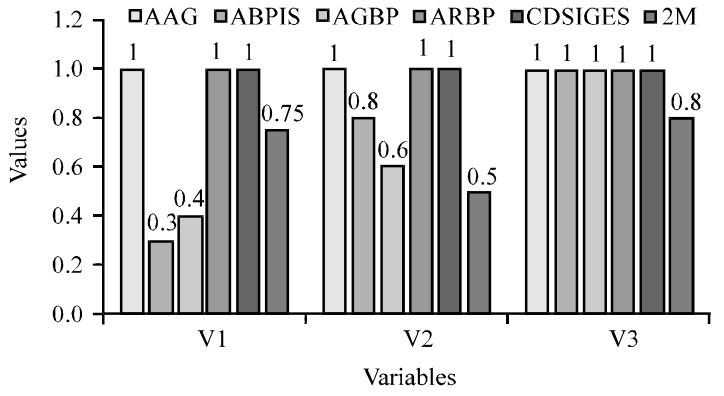

Fig. 5: Evolution of AAG metrics

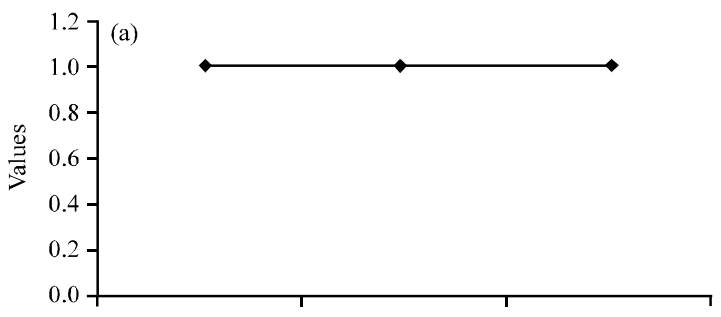

(b)

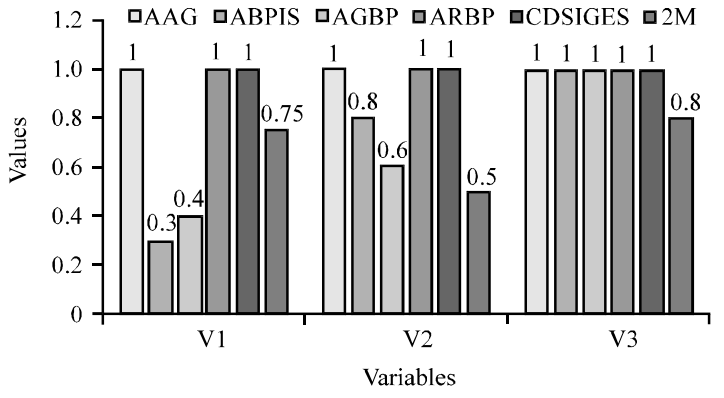

Fig. 6: a, b) Evolution of ARBP metrics

The goalof this metric is to evaluate the degree of alignment between the business processes and information system through business area. Blocks dedicated to support a business process and each area corresponds to a single business process. In the same way as the previous metric, there is an improvement in values from $0.3-1$.

The goal of this metric is to evaluate the degree of presence of actors in construction of alignment between the goals and business processes that support them. Actors depend on each other for goals to 
be achieved, tasks to be performed and resources to be furnished. By depending on others, an actor may be able to achieve goals that are difficult or impossible to achieve. Actors are strategic in the sense that they are concerned about opportunities and vulnerabilities and seek rearrangement of their environments that would better serve their interests by restructuring intentional relationships. The value of this metric is always equal to 1 view that all the actors contributed to the construction of the alignment of the project.

Average number of "resource" used by "business process" is computed counting the number of "resource" used by "business process "supporting a "hard goal" divided by the number of "resource". In the same way as the previous metric, there is an improvement in values from $0.5-1$.

\section{CONCLUSION}

In this study the researchers proposed a set of strategic alignment evaluation and evolution metrics, namely: average number of "hard goal" supported by "business process", average number of "resource" used by "business process", Average number of "actor" who contributed to make decision and achieve a "hard goal" and average number of "business process" supported by "IS business area".

These metrics have demonstrated the importance of integrating all elements of the enterprise architecture into the alignment construction. The study of the evolution of the metrics has demonstrated the possibility of detecting the problems of strategic alignment by visualizing all the elements that pose a problem of dysfunction of the alignment process. Our approach has shown the possibility of detecting the failure of the alignment process and identifying evolutionary requirements to build a corrected To-Be situation.

With these metrics as described in the case study in this study, the manager has a set of indicators for evaluate the degree of alignment between the goals in strategic level and information system.

Also these metrics allow to give a roadmap for the manager through the analysis of the gaps and the identification of the problems of the business IT alignment. However, the researchers recognized that much more testing on the metrics should be developed in order to assess its merit and significance.

\section{REFERENCES}

Anonymous, 2004. [Dynamics of relations around information systems in the management teams of large French companies]. CIGREF, Paris, France.
Bleistein, S.J., 2006. B-SCP: An integrated approach for validating alignment of organizational IT requirements with competitive business strategy. Ph.D Thesis, University of New South Wales, Kensington, Australia.

Bodhuin, T., R. Esposito, C. Pacelli and M. Tortorella, 2004. Impact analysis for supporting the Co-evolution of business processes and supporting software systems. Proceedings of the 5th International Workshop on Business Process Modeling, Development and Support (BPMDS'04), June 7-8, 2004, University of Latvia, Riga, Latvia, pp: 146-150.

Boehm, B.W., J.R. Brown, H. Kaspar, M. Lipow and G. MacLeod et al., 1978. Characteristics of Software Quality. North-Holland Publishing Company, Amsterdam, The Netherlands,

Borek, A., A.K. Parlikad, M. Helfert and M. Ge, 2011. An information oriented framework for relating IS/IT resources and business value. Proceedings of the 13th International Conference on Enterprise Information Systems (ICEIS'11), June 8-11, 2011, Beijing Jiaotong University, Beijing, China, pp: 358-367.

Brocke, J.V. and M. Rosemann, 2012. Handbook on Business Process Management: Strategic Alignment, Governance, People and Culture. Springer, Berlin, Germany,

Cavano, J.P. and J.A. McCall, 1978. A framework for the measurement of software quality. Proceedings of the ACM International Conference on SIGMETRICS Performance Evaluation Review Vol. 7, November 3-4, 1978, ACM, New York, USA., pp: 133-139.

Chan, Y.E. and B.H. Reich, 2007. IT alignment: What have we learned?. J. Inf. Technol., 22: 297-315.

Chan, Y.E., S.L. Huff, D.W. Barclay and D.G. Copeland, 1997. Business strategic orientation, information systems strategic orientation, strategic alignment. Inf. Syst. Res., 8: 125-150.

Chang, M.K., W. Cheung, C.H. Cheng and J.H. Yeung, 2008. Understanding ERP system adoption from the user's perspective. Intl. J. Prod. Econ., 113: 928-942.

Dormey, G.R., 1995. A model for software product quality. IEEE Trans. Software Eng., 21: 146-162.

Doumi, K., S. Baina and K. Baina, 2011a. Experimenting a modeling approach for modeling enterprise strategy in the context of strategic alignment. Proceedings of the 2011 International Conference on Enterprise Information Systems (CENTERIS'11), October 5-7, 2011, Springer, Algarve, Portugal, ISBN: 978-3-642-24354-7, pp: 356-368. 
Doumi, K., S. Baina and K. Baina, 2011b. Modeling approach for business IT alignment. Proceedings of the 13th International Conference on Enterprise Information Systems (ICEIS'11), June 8-11, 2011, Beijing Jiaotong University, Beijing, China, ISBN:978-989-8425-56-0, pp: 457-464.

Doumi, K., S. Baina and K. Baina, 2013a. Aligning organization's strategy to information system: The BUSITAME method application to university information system. Intl. J. Comput. Sci. Issues, 10: 201-211.

Doumi, K., S. Baina and K. Baina, 2013a. Strategic business and it alignment: Representation and evaluation. J. Theor. Appl. Inf. Technol., 47: 41-52.

Dyson, R.G., 1990. Strategic Planning: Models and Analytical Techniques. John Wiley \& Sons, Hoboken, New Jersey, USA., ISBN:9780471924913, Pages: 313.

Etien, A., 2006. [Alignment engineering: Concepts, models and processes]. Ph.D Thesis, Pantheon-Sorbonne University, Paris, France. (In French)

Fimbel, E., 2007. [Strategic Alignment-Synchronize Information Systems with Business Trajectories and Maneuvers]. Pearson, New York, USA., ISBN:978-2-7440-7226-0, Pages: 370 (In French).

Fitzpatrick, R., 1996. Software quality: Definitions and strategic issues. Master Thesis, Report Produced for the School of Computing, Staffordshire University, Stoke-on-Trent, England, UK.

Fritscher, B. and Y. Pigneur, 2011. Business IT alignment from business model to enterprise architecture. Proceedings of the 2011 International Workshops on Advanced Information Systems Engineering, June 20-24, 2011, Springer, London, England, UK., ISBN:978-3-642-22055-5, pp: 4-15.

Henderson, J. and H. Venkatraman, 1993. Strategic alignment: Leveraging information technology for transforming organizations. IBM Syst. J., 32: 472-484.

Hirschheim, R. and R. Sabherwal, 2001. Detours in the path toward strategic information systems alignment. California Manage. Rev., 44: 87-108.

Kearns, G.S. and A.L. Lederer, 2003. A resource-based view of strategic IT alignment: How knowledge sharing creates competitive advantage. Decis. Sci., 34: 1-29.

Krishna, A., A.K. Ghose and S.A. Vilkomir, 2004. Co-evolution of complementary formal and informal requirements. Proceedings of the 7 th International Workshop on Principles of Software Evolution, September 7, 2004, IEEE, Kyoto, Japan, pp: 159-164.

Lankhorst, M., 2012. Enterprise Architecture at Work: Modelling, Communication and Analysis. 3rd Edn., Springer, Berlin, Germany, ISBN:978-3-642-29650-5, Pages: 337.
Leede, J.D., J.C. Looise and B.C. Alders, 2002. Innovation, improvement and operations: An exploration of the management of alignment. Intl. J. Technol. Manage., 23: $353-368$

Luftman, J., 2000. Assessing business-IT alignment maturity. Commun. Assoc. Inf. Syst., 4: 1-50.

Mckeen, J.D. and H.A. Smith, 2003. Making IT Happen: Critical Issues in IT Management. John Wiley \& Sons, Hoboken, New Jersey, USA., ISBN: 9780470850879, Pages: 384.

Newkirk, H.E. and A.L. Lederer, 2007. The effectiveness of strategic information systems planning for technical resources, personnel resources and data security in environments of heterogeneity and hostility. J. Comput. Inf. Syst., 47: 34-44.

Peppard, J., 2003. Managing IT as a portfolio of services. Eur. Manage. J., 21: 467-483.

Redoli, J., R. Mompo, J. Garcia-Diez and $\mathrm{M}$. Lopez-Coronado, 2008. A model for the assessment and development of internet-based information and communication services in small and medium enterprises. Technovation, 28: 424-435.

Regev, A.W., 2004. Remaining fit: On the creation and maintenance of fit. Proceedings of the 5th International Workshop on Business Process Modeling, Development and Support (BPMDS'04), June 7-8, 2004, University of Latvia, Riga, Latvia, pp: 131-137.

Salinesi, C. and L.H. Thevenet, 2008. [Enterprise architecture, practical problems to innovation (In French)]. Inf. Syst. Eng., 13: 75-105.

Thevenet, L.H. and C. Salinesi, 2007. Aligning IS to organization's strategy: The InStAl method. Proceedings of the 19th International Conference on Advanced Information Systems Engineering (CAiSE'07), June 11-15, 2007, Springer, Trondheim, Norway, ISBN:978-3-540-72987-7, pp: 203-217.

Wagter, R., H.E. Proper and D. Witte, 2012. A practice-based framework for enterprise coherence. Proceedings of the 4th International Working Conference on Practice-Driven Research on Enterprise Transformation (PRET'12), June 27, 2012, Springer, Gdansk, Poland, ISBN:978-3-642-31133-8, pp: 77-95.

Wegmann, A., G. Regev, I. Rychkova, L.S. Le and P. Julia, 2007. Business and IT alignment with SEAM for enterprise architecture. Proceedings of the 11th IEEE International Conference on Enterprise Distributed Object Computing (EDOC'07), October 15-19, 2007 , IEEE, Annapolis, Maryland, ISBN:978-0-7695-2891-5, pp: 111-111.

Yu, E.S., 1997. Towards modelling and reasoning support for early-phase requirements Engineering. Proceedings of the 3rd IEEE International Symposium on Requirements Engineering, January 6-10, 1997, IEEE, Annapolis, Maryland, pp: 226-235. 